\title{
Bromophycolides C-I from the Fijian Red Alga Callophycus
}

\section{serratus}

\author{
Julia Kubanek ${ }^{\dagger, \ddagger},{ }^{,}$, Anne C. Prusak ${ }^{\dagger}$, Terry W. Snell ${ }^{\dagger}$, Rachel A. Giese ${ }^{\ddagger}$, Craig R. Fairchild§, \\ William Aalbersberg ${ }^{\perp}$, and Mark E. Hay ${ }^{\dagger}$ \\ $\uparrow$ School of Biology, Georgia Institute of Technology, Atlanta, GA, USA 30332 \\ $¥$ School of Chemistry and Biochemistry, Georgia Institute of Technology, Atlanta, GA, USA 30332 \\ §Bristol-Myers Squibb Pharmaceutical Research Institute, Princeton, NJ, USA 08543 \\ $\perp$ Institute of Applied Sciences, University of the South Pacific, Suva, Fiji
}

\begin{abstract}
Bromophycolides C-I (1-7) were isolated from extracts of the Fijian red alga Callophycus serratus, and identified by NMR and mass spectral techniques. These novel natural products share a carbon skeleton and biosynthetic origin with previously identified bromophycolides A (8) and B (9), which form a rare group of diterpene-benzoate macrolides. Bromophycolides C-I (1-7) displayed modest antineoplastic activity against a range of human tumor cell lines.
\end{abstract}

Marine red algae have been the source of numerous isoprenoid and phenolic metabolites, ${ }^{1}$ although natural products of combined isoprenoid and shikimate biosynthetic origin are less common. As part of a continuing investigation of bioactive substances from Fijian coral reef organisms, we recently reported the identification of three structurally unusual diterpenebenzoate macrolides from the red alga Callophycus serratus. ${ }^{2}$ Herein, we provide data in support of the identification of seven related compounds, bromophycolides C-F (1-7), whose structures were elucidated by NMR and mass spectral analyses and by comparison with previously isolated bromophycolides A-B (8-9) and debromophycolide A (10).

\section{Results and discussion}

Guided by a toxicity assay using ingestion rates of the invertebrate Brachionus calyciflorus (Rotifera), ${ }^{3}$ extracts of Callophycus serratus were separated by liquid-liquid partitioning, reversed-phase HPLC, and normal-phase HPLC, yielding bromophycolides C-I (1-7), which each represented $0.027-0.092 \%$ of algal dry mass (see Experimental section for details).

Bromophycolide C (1), with an ESI molecular ion of $\mathrm{m} / z 599.1010$ suitable for molecular formula $\mathrm{C}_{27} \mathrm{H}_{38} \mathrm{O}_{5} \mathrm{Br}_{2}$, appeared to differ from previously identified bromophycolide $\mathrm{A}(\mathbf{8})^{2}$ only by the substitution of a bromine for a hydroxyl group. Comparison of NMR spectral data for $\mathbf{1}$ (Table 1; Supporting information) and for $\mathbf{8}^{2}$ suggested that the sole difference lay near the diterpene head. Specifically, the resonance for C-15 of 8 occurred at $\delta 67.3$, compared with $\delta 72.0$ in 1. Position 14 , curiously, was not greatly affected $\left({ }^{13} \mathrm{C} \delta 81.7\right.$ vs. $80.4 ;{ }^{1} \mathrm{H} \delta 4.75$ vs. 4.65, for $\mathbf{1}$ and $\mathbf{8}$, respectively), but ${ }^{13} \mathrm{C}$ chemical shifts for positions 13, 26, and 27 in $\mathbf{1}$ were

*To whom correspondence should be addressed: telephone: 404-894-8424; fax: 404-385-4440; email: julia.kubanek@biology.gatech.edu.

Supporting Information Available: COSY, HMBC, and NOE data, and ${ }^{1} \mathrm{H}$ NMR spectra for $\mathbf{1}-\mathbf{7}$, available free of charge via the Internet at http://pubs.acs.org. 
2-7 ppm downfield relative to these positions in 8 . All other ${ }^{13} \mathrm{C}$ and ${ }^{1} \mathrm{H}$ chemical shifts for $\mathbf{1}$ and $\mathbf{8}$ were within $c a .1 \mathrm{ppm} .{ }^{1} \mathrm{H}-{ }^{1} \mathrm{H}$ scalar couplings were also very similar for $\mathbf{1}$ and $\mathbf{8}$, suggesting that their relative configurations did not differ. In particular, H-14 appeared as a doublet of doublets $(J=2$ and $11 \mathrm{~Hz})$ for both $\mathbf{1}$ and $\mathbf{8}$, establishing a common dihedral relationship to the two H-13 protons, consistent with the $14 S$ configuration previously confirmed by the X-ray crystal structure of $\mathbf{8} .^{2}$ Given that no other differences between $\mathbf{1}$ and $\mathbf{8}$ were apparent, we predict that $\mathbf{1}$ shares the absolute stereochemistry of $\mathbf{8}^{2,4}$

Bromophycolide D (2) also seemed to be structurally similar to $\mathbf{8}$, with an identical molecular formula $\left(\mathrm{C}_{27} \mathrm{H}_{37} \mathrm{O}_{4} \mathrm{Br}_{3}\right.$ from $[\mathrm{M}-\mathrm{H}]^{-} \mathrm{m} / z$ 661.0190). The difference occurred near the diterpene-aryl junction, where instead of a tetra-substituted olefin at C-6-C-19 as in 8, DEPT and HSQC analysis indicated an exo-methylene group (C-23). In $\mathbf{2}$, the two H-23 singlets $(\delta$ 4.88 and 5.18) showed HMBC correlations to C-6 ( $\delta 49.0)$ and to C-20 ( $\delta 37.4)$, as well as COSY correlations to each other, to H-6 ( $\delta$ 2.63), and to H-20a ( $\delta 2.09)$ (Supporting information). Three protons, H-5b ( $\delta 3.14), \mathrm{H}-6$, and H-21b $(\delta 2.27)$, showed HMBC correlations to C-19 ( $\delta$ 145.7), establishing the exo-methylene attachment to C-19.

In 2, the existence of an unsaturation at C-19-C-23 introduced a stereocenter at C-6 that was not present in $\mathbf{1}$ or $\mathbf{8}$. From a strong NOE observed between H-6 and H-22 ( $\delta 4.32)$ (Supporting information), this stereocenter could readily be assigned an $R$ configuration, which was further supported by NOEs between H-6 and H-8b $(\delta 2.36)$, H-6 and H-3 ( $\delta$ 7.92), and the lack of an observable NOE between H-6 and Me-24 ( $\delta 0.93)$. According to the X-ray crystal structure of $\mathbf{8}^{2}$ the plane of the $p$-hydroxybenzoate group was approximately orthogonal to the plane of the cyclohexene group in $\mathbf{8}$; if this conformation was not grossly altered in $\mathbf{2}$, only a $6 R$ configuration could lead to the observed NOE between the aryl H-3 and H-6. In fact, all $C$. serratus natural products displaying the C-19-C-23 unsaturation (2-4, 6-7) exhibited NOE correlations supporting a $6 R$ configuration (Supporting information).

From chemical shifts of carbons and protons in the vicinity of the diterpene head (Table 1), $\mathrm{C}-15$ in 2 ( $\delta$ 67.6) appeared to be substituted with $\mathrm{Br}$ (as in 8) and not $\mathrm{OH}$ (as in 1). However, the scalar couplings between $\mathrm{H}-14$ and the two $\mathrm{H}-13$ protons in $\mathbf{2}$ were dissimilar to either $\mathbf{1}$ or 8: $\mathrm{H}-14$ was a pseudotriplet with $J=6.5 \mathrm{~Hz}$, suggesting 5 dihedral angles in the range of 20 $-30^{\circ}$ or $130-140^{\circ}$ between $\mathrm{H}-14$ and its $\mathrm{H}-13$ neighbors, rather than the gauche and anti relationships predicted by the X-ray crystal structure of $\mathbf{8}^{2}$ or the gauche/gauche relationships predicted if the configuration at $\mathrm{C}-14$ was opposite to that of $\mathbf{8}$ but the overall conformation was identical. As a result, we became concerned that the macrolide conformation differed significantly between $\mathbf{2}$ and $\mathbf{8}$, and so we turned to NOEs to assess the conformation and stereochemistry of $\mathbf{2}$. NOEs were observed between aryl H-3 ( $\delta 7.92)$ and aliphatic H-12a for both 2 and $\mathbf{8}^{2}$, requiring H-12a to be pointing towards the aryl group in both compounds as predicted by the X-ray structure of $\mathbf{8}^{2}(\mathrm{H}-3-\mathrm{H}-12$ a distance $=3.3 \AA$; Figure 1$)$. This suggested that the aryl-macrolide spatial relationship was similar for $\mathbf{2}$ and $\mathbf{8}$ despite different H-13-H-14 dihedral angles. In fact, $\mathrm{H}-13-\mathrm{H}-14$ dihedral angles of $20-30^{\circ}$ and $130-140^{\circ}$ for 2 could be accommodated without grossly distorting the conformation shown in Figure 1. Most importantly, NOESY correlations evident between H-14 and both H-12 ( $\delta 1.53$ and 2.28) (Supporting information) confirmed this spatial relationship, consistent only with a $14 \mathrm{~S}$ configuration for $\mathbf{2}$, as with $\mathbf{8}$ for which $\mathrm{H}-12-\mathrm{H}-14$ inter-atomic distances were $2.6-2.8 \AA$ (Figure 1).

Bromophycolide E (3), with a $[\mathrm{M}-\mathrm{H}]^{-}$ion at $m / z 581.0935$ appropriate for a molecular formula of $\mathrm{C}_{27} \mathrm{H}_{36} \mathrm{O}_{4} \mathrm{Br}_{2}$, appeared to differ from 2 only by the loss of $\mathrm{HBr}$ from the diterpene head. Examination of ${ }^{1} \mathrm{H}$ and DEPT NMR data for $\mathbf{3}$ indicated one fewer methyl group than in $\mathbf{2}$, and an additional olefin, disubstituted at C-15 ( $\delta 141.0)$ (Table 1). Me-27 $\left({ }^{1} \mathrm{H} \delta 1.79\right)$ showed HMBC correlations to C-14 ( $\delta 76.8), \mathrm{C}-15$, and C-26 ( $\delta$ 111.2) (Supporting information). The 
two H-26 vinyl singlets ( $\delta 4.85,4.95)$, in turn, showed HMBC correlations to C-14 and C-27, as well as COSY correlations to $\mathrm{H}-14$ ( $\delta 5.14)$, establishing the isopropylene attachment at C-14. Assignment of stereochemistry for C-14 by NOE analysis (Supporting information) was somewhat hampered by partial overlap of ${ }^{1} \mathrm{H}$ NMR signals for $\mathrm{H}-12 \mathrm{~b}$ and $\mathrm{H}-13 \mathrm{~b}$. However, NOESY correlations appeared to indicate the proximity of $\mathrm{H}-14$ to all four protons at positions 12 and 13 , and of aryl H-3 ( $\delta 7.80)$ to H-12b, suggesting a $14 S$ configuration for $\mathbf{3}$, according to the arguments set forward for 2 .

Bromophycolide $\mathrm{F}$ (4) appeared to possess a molecular formula of $\mathrm{C}_{27} \mathrm{H}_{37} \mathrm{O}_{5} \mathrm{Br}$ from its parent ion with $\mathrm{m} / z$ 519.1773, representing one additional site of unsaturation relative to 1 due to the loss of $\mathrm{HBr}$. However, rather than elimination leading to an olefin, NMR data suggested the presence of an epoxide group within 4 (Table 1; Supporting information). The location of the epoxide was established from HMBC correlations from Me-25 $(\delta 1.34)$ to the two epoxide centers C-10 $(\delta 67.1)$ and C-11 ( $\delta 64.0)$, from H-10 $(\delta 2.77)$ to C-9 $(\delta 24.7)$, and by a COSY correlation between $\mathrm{H}-10$ and $\mathrm{H}-9 \mathrm{a}(\delta 1.62)$. This epoxide possessed a $10 S, 11 S$ (trans) configuration previously seen in debromophycolide $\mathrm{A}(\mathbf{1 0}),{ }^{2}$ supported for 4 by NOEs between $\mathrm{H}-10$ and $\mathrm{H}-9 \mathrm{~b}$ ( $\delta 2.01)$; H-10 and H-12a ( $\delta 1.03)$; Me-25 and H-9a; Me-25 and H-12b ( $\delta 1.99)$; but not between H-10 and Me-25. An NOE between H-10 and H-6 ( $\delta 3.50)$ supporting the $10 S$ configuration linked the epoxide stereochemistry to other confirmed chiral centers in the molecule. As with $\mathbf{2}$ and $\mathbf{3}$, NOEs established a $14 S$ configuration for $\mathbf{4}$, due to NOESY correlations from $\mathrm{H}-14(\delta 4.48)$ to $\mathrm{H}-12 \mathrm{a}$, and from $\mathrm{H}-3(\delta 8.17)$ to $\mathrm{H}-12 \mathrm{a}$.

The structures described above all shared a 15-membered lactone framework. A second major group of cyclization products was also identified, possessing a 16-membered macrolide skeleton similar to the previously identified bromophycolide B (9).

The mass spectrum of bromophycolide $\mathrm{G}(\mathbf{5})$, with an $[\mathrm{M}-\mathrm{H}]^{-} \mathrm{m} / \mathrm{z}$ of 599.1038 , satisfied a molecular formula of $\mathrm{C}_{27} \mathrm{H}_{38} \mathrm{O}_{5} \mathrm{Br}_{2}$, representing a substitution of $\mathrm{Br}$ for $\mathrm{OH}$ relative to 9 . A comparison of ${ }^{1} \mathrm{H}$ and ${ }^{13} \mathrm{C}$ chemical shifts for 5 (Table 1) and $\mathbf{9}^{2}$ suggested that these two compounds differed only at one site. The most affected resonance was that of C-14 ( $\delta 74.5$ for $\mathbf{5}$ vs. 61.6 for $\mathbf{9}$ ), inferring that in $\mathbf{5}$ there was a hydroxyl at C-14. HMBC and COSY data supported the conclusion that other regions of the molecule remained identical for these two compounds (Supporting information).

Analysis of NOESY and ROESY data for $\mathbf{5}$ (Supporting information) confirmed that most stereochemistry was shared between $\mathbf{5}$ and $\mathbf{9}$. For $\mathbf{5}$, NOEs were observed between H-10 $(\delta$ $3.30)$ and Me-25 ( $\delta 1.16)$ establishing the bromohydrin stereochemistry as $10 R, 11 S$; and NOEs between $\mathrm{H}-22(\delta 4.44)$ and $\mathrm{H}-8 \mathrm{~b}(\delta 1.81), 9 \mathrm{a}(\delta 1.57)$, and $9 \mathrm{~b}(\delta 1.84)$ confirmed the cyclohexene-region stereochemistry as $7 S, 22 S$. However, the configuration at position 14 in 5 appeared to be opposite that of $\mathbf{9}$. For $\mathbf{9}$, NOESY correlations were observed between H-14 and both Me-26 and Me-27, consistent with its X-ray crystal structure, which confirmed a $14 R$ configuration and established distances of 2.4-2.6 ̊̊ between H-14 and these methyl protons in 9 (Figure 2). ${ }^{2}$ In contrast, for $\mathbf{5}$, NOESY and ROESY correlations were observed only between $\mathrm{H}-14(\delta 4.22)$ and Me-27 ( $\delta 1.71)$, and not between H-14 and Me-26 ( $\delta 1.47)$, consistent with an assignment of $14 S$ for $\mathbf{5}$, in which $\mathrm{H}-14$ would be expected to be anti to one of the methyl groups and thus less likely to result in a significant observable NOE (Figure 2).

Bromophycolide $\mathrm{H}(\mathbf{6})$, with a parent ion at $m / z 661.0183$ (suitable for a molecular formula of $\mathrm{C}_{27} \mathrm{H}_{37} \mathrm{O}_{4} \mathrm{Br}_{3}$ ), was isomeric with $\mathbf{2 , 8}$, and $\mathbf{9}$, but comparison of NMR spectral data ${ }^{2}$ suggested the closest relationship to $\mathbf{9}$ (Table 1). However, $\mathbf{6}$ appeared to share the C-19-C-23 unsaturation of 2-4 (Supporting information). The stereochemistry at C-14 of $\mathbf{6}$ appeared to be $R$ as in $\mathbf{9}$, due to observed NOEs between H-14 ( $\delta 4.01)$ and both methyls at positions 26 and 27 ( $\delta 1.73$ and 1.84 , respectively), consistent with the X-ray crystal structure of 9.2 
The molecular formula for bromophycolide I (7) was confirmed to be $\mathrm{C}_{27} \mathrm{H}_{38} \mathrm{O}_{5} \mathrm{Br}_{2}$ from the parent ion at $m / z$ 599.0964, isomeric with 1 and 5. From NMR data (Table 1; Supporting information), it was apparent that $\mathbf{7}$ was a hybrid of 5 and $\mathbf{6}$, incorporating the exo-methylene of $\mathbf{6}$ at C-19-C-23 and the hydroxyl group of 5 at C-14. As with $\mathbf{5}$, observable NOEs between $\mathrm{H}-14(\delta 3.58)$ and only one of the diterpene head methyls (Me-27 $\delta 1.73)$ suggested a $14 S$ configuration for 7 .

Given the obvious structural similarities between bromophycolides C-I (1-7) and previously identified bromophycolides A-B (8-9), it seems probable that 1-4 and $\mathbf{8}$ were biosynthesized from a common precursor, as were 5-7 and 9. The C-19-C-23 unsaturation in 2-4 and 6-7 would likely have resulted as the kinetically-favored product following the six-membered ringclosing event within the diterpene fragment (see Scheme 1 in ref. ${ }^{2}$ ). Bromines and oxygens in the diterpene portions of 1-9 were all attached to carbons expected to be unsaturated in a biosynthetic precursor, consistent with electrophilic addition of bromine as previously observed. 6,7

Compounds 1-7 showed modest antineoplastic activity against a range of human tumor cell lines (Table 2). The most selective of these was bromophycolide $\mathrm{H}(\mathbf{6})$, with its strongest activity against breast tumor cell line DU4475 $\left(\mathrm{IC}_{50}=3.88 \mu \mathrm{M}\right)$. Limited consideration of structure-activity relationships including comparisons involving bromophycolides A (8), B (9), and debromophycolide $\mathrm{A}(\mathbf{1 0})^{2}$ suggested that replacing $\mathrm{Br}$ at position 15 of $\mathbf{8}$ was detrimental to the cytotoxic potency, whereas the contribution of $\mathrm{Br}$ replacement in other portions of the bromophycolide structure was less clear. Removal of all bromines and/or alteration of the carbon skeleton as in $\mathbf{1 0}$ resulted in abolishment of measurable cytotoxicity. Among the bromophycolides, there does not appear to be a clear pattern connecting antineoplastic activity with the mode of cyclization (i.e., 15-membered macrolides 1-4, 8 vs. 16-membered macrolides 5-7,9), although 15 -membered macrolide 8 remains the most potent cytotoxin of this class of natural products. ${ }^{2}$ Bromophycolide $\mathrm{F}(\mathbf{4})$ and I (7) demonstrated weak antifungal activity, being $70-80 \%$ less active than 8 or 9,2 and the remaining bromophycolides showed no significant antifungal activity.

In conclusion, we have identified seven novel bioactive natural products (1-7) that share a diterpenebenzoate carbon skeleton which has so far been observed from only one source, Callophycus serratus, a member of the understudied red algal family Solieriaceae. ${ }^{2}$ This discovery expands to 10 the number of known compounds that apparently combine benzoate and terpene biosynthetic precursors to yield macrolide products.

\section{Experimental section}

\section{General experimental procedures}

UV spectra were recorded in methanol with a Spectronic 21D spectrophotometer. Optical rotations were measured on a Jasco P-1010 spectropolarimeter. NMR spectra were acquired on a Bruker DRX-500 instrument, using a 5 mm inverse detection probe for ${ }^{1} \mathrm{H}, \mathrm{COSY}$, HSQC, and HMBC experiments, and a $5 \mathrm{~mm}$ broadband probe for ${ }^{1} \mathrm{H},{ }^{13} \mathrm{C}$, DEPT-135, DEPT-90, NOESY, and ROESY experiments. Difference NOE spectra were acquired on a Varian Mercury Vx $400 \mathrm{MHz}$ NMR spectrometer. For some compounds, quaternary carbon chemical shifts were inferred from HMBC data. High-resolution mass spectra were generated using electrospray ionization with an Applied Biosystems QSTAR-XL hybrid Quadrupole-Time-ofFlight tandem mass spectrometer and Analyst QS software. LC-MS analyses were conducted using a Waters 2695 HPLC with Waters 2996 diode-array UV detection and Micromass ZQ 2000 mass spectrometer with electrospray ionization. LC-MS chromatography was achieved with an Xterra NS- $\mathrm{C}_{18} 3.5 \mu \mathrm{m}$ column measuring $2.1 \times 15 \mathrm{~mm}$, and gradient mobile phases of aqueous methanol with $0.1 \%$ acetic acid. Semi-preparative HPLC was performed using a 
Waters 1525 or 515 pump, with a Waters 2487 dual wavelength absorbance detector, controlled by Waters Breeze Version 3.20 software. Compound purification by HPLC was achieved using Agilent Zorbax SB-C 18 and RX-SIL columns $(5 \mu \mathrm{m}, 9.4 \times 250 \mathrm{~mm})$. All commercial chemicals were reagent grade, except for solvents used for HPLC and LC-MS, which were HPLC or Optima grade (Fisher Scientific Co.). NMR solvents were purchased from Cambridge Isotope Laboratories.

\section{Biological material}

Callophycus serratus (Harvey ex Kutzing 1957) (family Solieriaceae, order Gigartinales, class Rhodophyceae, phylum Rhodophyta) was collected at depths of 2-20 m from several sites in Fiji: Fish Patch Reef near Suva (18 09' 36" S, $178^{\circ} 23^{\prime} 58^{\prime \prime}$ E), Makaluva Passage near Suva

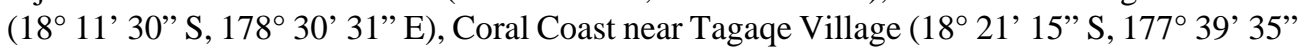

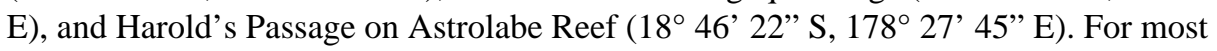
collections, fresh C. serratus was frozen at $-20^{\circ} \mathrm{C}$ until extraction. One sample was placed directly in methanol and stored at $-20{ }^{\circ} \mathrm{C}$ until further processing. Voucher specimens were compared to morphological traits previously described ${ }^{8}$, placed in aqueous formaldehyde, and deposited at the University of the South Pacific.

\section{Pharmacological assays}

A previously described rotifer ingestion assay was used as a sublethal toxicity test for bioassayguided fractionation, performed with the freshwater rotifer species Brachionus calyciflorus. ${ }^{3}$ Crude extracts to be tested for toxicity were dissolved in acetone, diluted 99-fold with water, and then added to 24-well plate wells at $100 \mu \mathrm{g}$ extract per $\mathrm{mL}(\mathrm{n}=4$ wells for each extract tested). Chromatographic fractions were tested at concentrations proportional to their yield from the crude extract. Approximately 15 newborn rotifers were placed into each well containing $750 \mu \mathrm{L}$ of test solution and incubated at $23{ }^{\circ} \mathrm{C}$. Animals were exposed to test solutions for 45 minutes and then $10 \mu \mathrm{L}$ of a suspension of $1 \mathrm{mg}$ red carmine powder (Fisher Scientific Co., AC 19020-0050) per $2 \mathrm{~mL}$ water was introduced into each well to allow 15 minutes of feeding. The rotifers readily ingest these particles in the absence of toxicant stress. Rotifers with red guts were scored as feeding, and rotifers with no visible red were scored as non-feeding, using an Olympus dissecting microscope at $25 \times$ magnification. A one-way ANOVA was performed on these data with sample extract as the independent variable and percent of rotifers feeding as the dependent variable, comparing data for rotifers exposed to extracts (or chromatographic fractions), vs. rotifers exposed to carrier solvent (acetone) only.

Compounds were tested against a tumor cell line panel including breast, colon, lung, prostate, and ovary cancer cells. The cell lines used were: BT-549, DU4475, MDA-MD-468, NCI-H446, PC-3, SHP-77, LNCaP-FGC, HCT116, MDA-MB-231, A2780/DDP-S, and Du145. In vitro cytotoxicity was assessed by (3-(4,5-dimethylthiazol-2-yl)-5-(3-carboxymethoxyphenyl)-2(4-sulfophenyl)-2H-tetrazolium inner salt) MTS dye conversion assay as previously described. 9

For the antifungal assay, amphotericin B-resistant Candida albicans was grown overnight at $30{ }^{\circ} \mathrm{C}$ in RPMI media (Invitrogen). A hemocytometer was used to measure cell density, and cultures were diluted to $1 \times 10^{4}$ cells $/ \mathrm{mL}$. The indicator Alamar Blue 100 $\times$ (TREK Diagnostic Systems) was added to the cell suspension, and the cells added to microtiter plates. Compounds in DMSO were then added, serially diluted, and incubated $12-15$ hours at $37^{\circ} \mathrm{C}$. Amphotericin B $(0.5 \mathrm{mg} / \mathrm{mL})$ and DMSO were used as positive and negative controls, respectively. Colorimetric changes associated with the altered oxidation state of Alamar Blue (indicating cell proliferation) were assessed visually. 


\section{Isolation}

C. serratus was exhaustively extracted with water, methanol, and methanol/dichloromethane (1:1 and 1:2). The extracts were combined, reduced in vacuo, and partitioned between methanol/water (9:1) and petroleum ether. The aqueous fraction was adjusted to methanol/ water (6:4) and then partitioned against chloroform. The bioactive chloroform extract was fractionated by $\mathrm{C}_{18}$ reversed-phase HPLC using a gradient of methanol and water, followed by $\mathrm{C}_{18}$ reversed-phase HPLC using a gradient of acetonitrile and water. Finally, normal phase silica gel HPLC with hexane/ethyl acetate or hexane/diethyl ether led to bromophycolides CI (1-7). For some compounds, one further separation with reversed-phase HPLC was necessary for final purification. Pure compounds $(30 \mu \mathrm{g} / \mathrm{mL})$ were analyzed by LC-MS to assess purity, $\lambda_{\max }$, and nominal molecular mass.

Bromophycolide C (1) was obtained as a white amorphous solid (1.0 mg; $0.027 \%$ plant dry mass); $[\alpha]^{23} \mathrm{D}+12^{\circ}\left(\right.$ c $\left.0.032 \mathrm{~g} / 100 \mathrm{~mL}, \mathrm{CHCl}_{3}\right) ; \mathrm{UV}(\mathrm{MeOH}) \lambda_{\max }(\log \varepsilon) 265(3.21) \mathrm{nm} ;{ }^{1} \mathrm{H}$ NMR $\left(\mathrm{CDCl}_{3}, 500 \mathrm{MHz}\right)$ and ${ }^{13} \mathrm{C} / \mathrm{DEPT}$ NMR $\left(\mathrm{CDCl}_{3}, 125 \mathrm{MHz}\right)$ data, Table 1; COSY, HMBC NMR data, Supporting Information; HRESIMS [M-H] ${ }^{-} \mathrm{m} / z 599.1010$ (calcd for $\mathrm{C}_{27} \mathrm{H}_{37} \mathrm{O}_{5} \mathrm{Br}_{2}$, 599.1013).

Bromophycolide D (2) was obtained as a white amorphous solid (3.6 mg; $0.081 \%$ plant dry mass): $[\alpha]^{23}{ }_{\mathrm{D}}+47^{\circ}\left(c 0.041 \mathrm{~g} / 100 \mathrm{~mL}, \mathrm{CHCl}_{3}\right)$; $\mathrm{UV}(\mathrm{MeOH}) \lambda_{\max }(\log \varepsilon) 264(3.88) \mathrm{nm} ;{ }^{1} \mathrm{H}$ NMR $\left(\mathrm{CDCl}_{3}, 500 \mathrm{MHz}\right)$ and ${ }^{13} \mathrm{C} / \mathrm{DEPT}$ NMR $\left(\mathrm{CDCl}_{3}, 125 \mathrm{MHz}\right)$ data, Table 1; NOE, COSY, HMBC NMR data, Supporting Information; HRESIMS [M-H] ${ }^{-} \mathrm{m} / z 661.0190$ (calcd for $\left.\mathrm{C}_{27} \mathrm{H}_{36} \mathrm{O}_{4} \mathrm{Br}_{3}, 661.0169\right)$.

Bromophycolide $\mathrm{E}(\mathbf{3})$ was obtained as a white amorphous solid (3.4 $\mathrm{mg} ; 0.092 \%$ plant dry mass): $[\alpha]^{23} \mathrm{D}+35^{\circ}$ ( $c 0.034 \mathrm{~g} / 100 \mathrm{~mL}, \mathrm{CHCl}_{3}$ ); $\mathrm{UV}(\mathrm{MeOH}) \lambda_{\max }(\log \varepsilon) 263(3.72) \mathrm{nm} ;{ }^{1} \mathrm{H}$ NMR $\left(\mathrm{CDCl}_{3}, 500 \mathrm{MHz}\right)$ and ${ }^{13} \mathrm{C} / \mathrm{DEPT}$ NMR $\left(\mathrm{CDCl}_{3}, 125 \mathrm{MHz}\right)$ data, Table 1 ; NOE, COSY, HMBC NMR data, Supporting Information; HRESIMS [M-H] $]^{-} \mathrm{m} / z 581.0935$ (calcd for $\mathrm{C}_{27} \mathrm{H}_{35} \mathrm{O}_{4} \mathrm{Br}_{2}$, 581.0908).

Bromophycolide F (4) was obtained as a white amorphous solid $(1.0 \mathrm{mg} ; 0.027 \%$ plant dry mass): $[\alpha]^{23} \mathrm{D}^{-8^{\circ}}\left(c 0.024 \mathrm{~g} / 100 \mathrm{~mL}, \mathrm{CHCl}_{3}\right) ; \mathrm{UV}(\mathrm{MeOH}) \lambda_{\max }(\log \varepsilon) 220(3.55), 263$ (3.42) $\mathrm{nm} ;{ }^{1} \mathrm{H}$ NMR $\left(\mathrm{CDCl}_{3}, 500 \mathrm{MHz}\right)$ and ${ }^{13} \mathrm{C} / \mathrm{DEPT}$ NMR $\left(\mathrm{CDCl}_{3}, 125 \mathrm{MHz}\right)$ data, Table 1 ; NOE, COSY, HMBC NMR data, Supporting Information; HRESIMS [M-H] ${ }^{-} \mathrm{m} / z 519.1773$ (calcd for $\mathrm{C}_{27} \mathrm{H}_{36} \mathrm{O}_{5} \mathrm{Br}, 519.1752$ ).

Bromophycolide $\mathrm{G}(\mathbf{5})$ was obtained as a white amorphous solid $(3.0 \mathrm{mg} ; 0.081 \%$ plant dry mass): $[\alpha]^{23} \mathrm{D}^{-2^{\circ}}$ ( $\left.c 0.013 \mathrm{~g} / 100 \mathrm{~mL}, \mathrm{CHCl}_{3}\right) ; \mathrm{UV}(\mathrm{MeOH}) \lambda_{\max }(\log \varepsilon) 217$ (3.95), 262 (3.84) $\mathrm{nm} ;{ }^{1} \mathrm{H}$ NMR $\left(\mathrm{CDCl}_{3}, 500 \mathrm{MHz}\right)$ and ${ }^{13} \mathrm{C} / \mathrm{DEPT} \mathrm{NMR}\left(\mathrm{CDCl}_{3}, 125 \mathrm{MHz}\right)$ data, Table 1 ; NOE, COSY, HMBC NMR data, Supporting Information; HRESIMS [M-H] ${ }^{-} \mathrm{m} / z 599.1038$ (calcd for $\mathrm{C}_{27} \mathrm{H}_{37} \mathrm{O}_{5} \mathrm{Br}_{2}$, 599.1013).

Bromophycolide $\mathrm{H}(\mathbf{6})$ was obtained as a white amorphous solid (3.1 mg; $0.084 \%$ plant dry mass): $[\alpha]^{23}{ }_{\mathrm{D}}+42^{\circ}\left(c 0.049 \mathrm{~g} / 100 \mathrm{~mL}, \mathrm{CHCl}_{3}\right)$; $\mathrm{UV}(\mathrm{MeOH}) \lambda_{\max }(\log \varepsilon) 263(3.68) \mathrm{nm} ;{ }^{1} \mathrm{H}$ NMR $\left(\mathrm{CDCl}_{3}, 500 \mathrm{MHz}\right)$ and ${ }^{13} \mathrm{C} / \mathrm{DEPT}$ NMR $\left(\mathrm{CDCl}_{3}, 125 \mathrm{MHz}\right)$ data, Table 1 ; NOE, COSY, HMBC NMR data, Supporting Information; HRESIMS [M-H] ${ }^{-} \mathrm{m} / z 661.0183$ (calcd for $\mathrm{C}_{27} \mathrm{H}_{36} \mathrm{O}_{4} \mathrm{Br}_{3}, 661.0169$ ).

Bromophycolide I (7) was obtained as a white amorphous solid (1.0 mg; $0.027 \%$ plant dry mass): $[\alpha]^{23} \mathrm{D}+36^{\circ}$ ( $c 0.011 \mathrm{~g} / 100 \mathrm{~mL}, \mathrm{CHCl}_{3}$ ); $\mathrm{UV}(\mathrm{MeOH}) \lambda_{\max }(\log \varepsilon) 262(3.70) \mathrm{nm} ;{ }^{1} \mathrm{H}$ NMR $\left(\mathrm{CDCl}_{3}, 500 \mathrm{MHz}\right)$ and ${ }^{13} \mathrm{C} / \mathrm{DEPT} \mathrm{NMR}\left(\mathrm{CDCl}_{3}, 125 \mathrm{MHz}\right)$ data, Table 1; NOE, COSY, HMBC NMR data, Supporting Information; HRESIMS [M-H] $]^{-} \mathrm{m} / z 599.0964$ (calcd for $\mathrm{C}_{27} \mathrm{H}_{37} \mathrm{O}_{5} \mathrm{Br}_{2}$, 599.1007). 


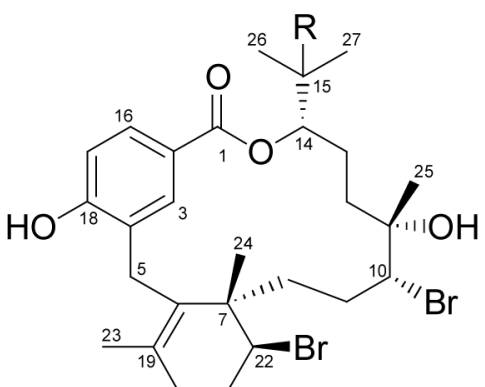

$1 \mathrm{R}=\mathrm{OH}$

$8 \mathrm{R}=\mathrm{Br}$

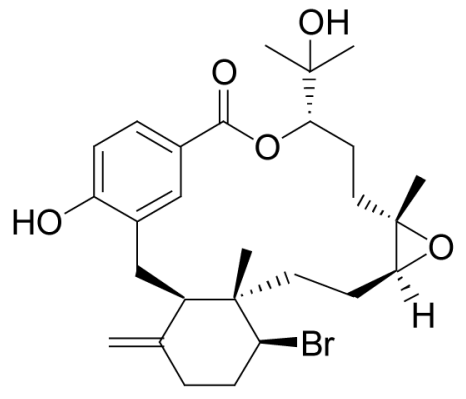

4<smiles>C=C1CC[C@H](Br)[C@]2(C)CC[C@H](Br)[C@@](C)(O)CC[C@H](O)C(C)(C)OC(=O)c3ccc(O)c(c3)C[C@@H]12</smiles>

7

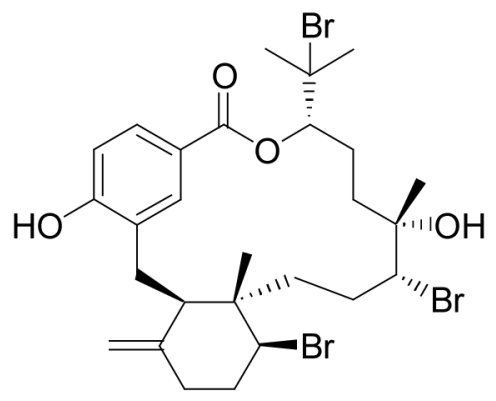

2

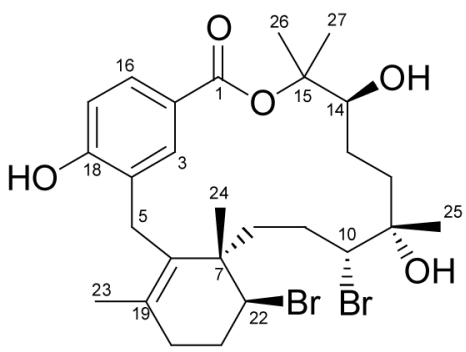

5

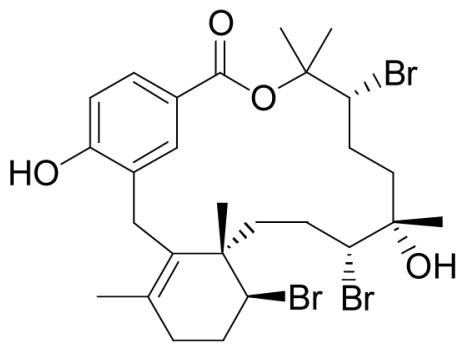

9

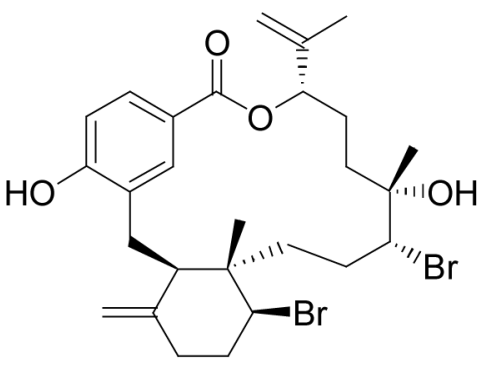

3<smiles></smiles>

6<smiles>[Z]C1=CC(/C(C)=C/[C@H](CC[C@@]2(C)O[C@@H]2C(C)(C)O)OC(=O)c2ccc(O)c(CC3=C([Z])[C@@H](C)CC3)c2)CC1</smiles>

10

\section{Supplementary Material}

Refer to Web version on PubMed Central for supplementary material.

\section{Acknowledgment}

This research was supported by an ICBG grant from the U.S. National Institutes of Health. The authors thank the Government of Fiji for permission to perform research in their territorial waters, and the people of Kadavu, Nadroga, and Rewa provinces for facilitating this work. We especially thank Ratu (Chief) Timoci Batirerega and the residents of Tagaqe village, and Ratu Kitione Qereqeretabua and the residents of Dravuni village. We thank W. Fenical, P. Jensen, and L. Zeigler at Scripps Institution of Oceanography for antifungal assay data; R. Peterson and K. Johnston at Bristol-Myers Squibb for performing antitumor assays; M.C. Sullards and D. Bostwick at the Georgia Tech Mass Spectrometry Laboratory and L. Gelbaum at the Georgia Tech NMR Center for spectroscopic expertise; and A. Bommarius, J. Broering, and K. Polizzi for use of their spectropolarimeter. We also acknowledge field assistance from A. Chequer, H. Hay, and K. Hay, and assistance with extractions from M. Sharma and K. Feussner at the University of the South Pacific. 


\section{References and notes}

1. Blunt JW, Copp BR, Munro MH, Northcote PT, Prinsep MR. Nat. Prod. Rep 2005;22:15-61. [PubMed: 15692616]

2. Kubanek J, Prusak AC, Snell TW, Giese RA, Hardcastle KI, Fairchild CR, Aalbersberg W, RaventosSuarez C, Hay ME. Org. Lett 2005;7:5261-5264. [PubMed: 16268553]

3. Snell, TW. Small-Scale Freshwater Environment Toxicity Test Methods. Blaise, C.; Ferard, JF., editors. Kluwer; Dordrecht: 2005.

4. The prediction of a shared absolute stereochemistry for 1 and 8 is made despite the opposite signs of their optical rotations, which were obtained for 1-7 using very low compound concentrations, and are therefore probably not reliable.

5. Silverstein, RM.; Webster, FX. Spectrometric Identification of Organic Compounds. 6 ed.. John Wiley \& Sons, Inc.; New York: 1998.

6. Murphy CD. J. Appl. Microbiol 2003;94:539-548. [PubMed: 12631188]

7. Butler A, Carter-Franklin JN. Nat. Prod. Rep 2004;21:180-188. [PubMed: 15039842]

8. Littler, DS.; Littler, MM. South Pacific Reef Plants. Offshore Graphics, Inc.; Washington, D.C.: 2003.

9. Lee FYF, Borzilleri R, Fairchild CR, Kim SH, Long BH, Raventos-Suarez C, Vite GD, Rose WC, Kramer RA. Clinical Cancer Res 2001;7:1429-1437. [PubMed: 11350914] 


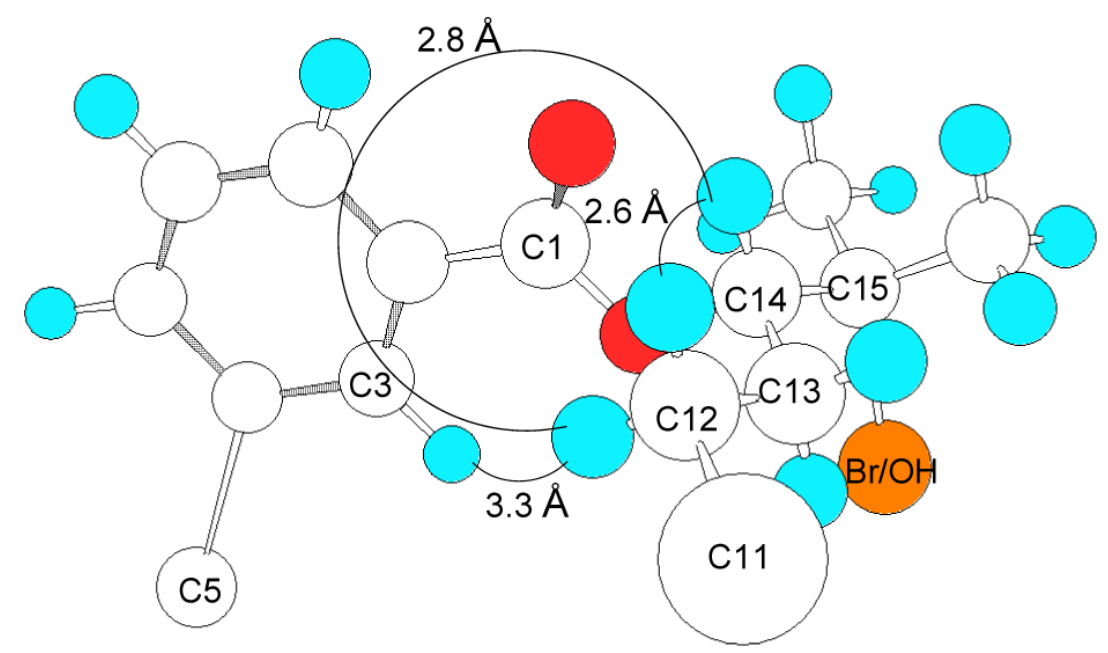

Figure 1.

Partial 3D structures of bromophycolides A (8), C (1), D (2), and F (4), predicted from the Xray crystal structure of $\mathbf{8}$ (ref. 2), indicating selected inter-atomic distances consistent with observed NOEs. 

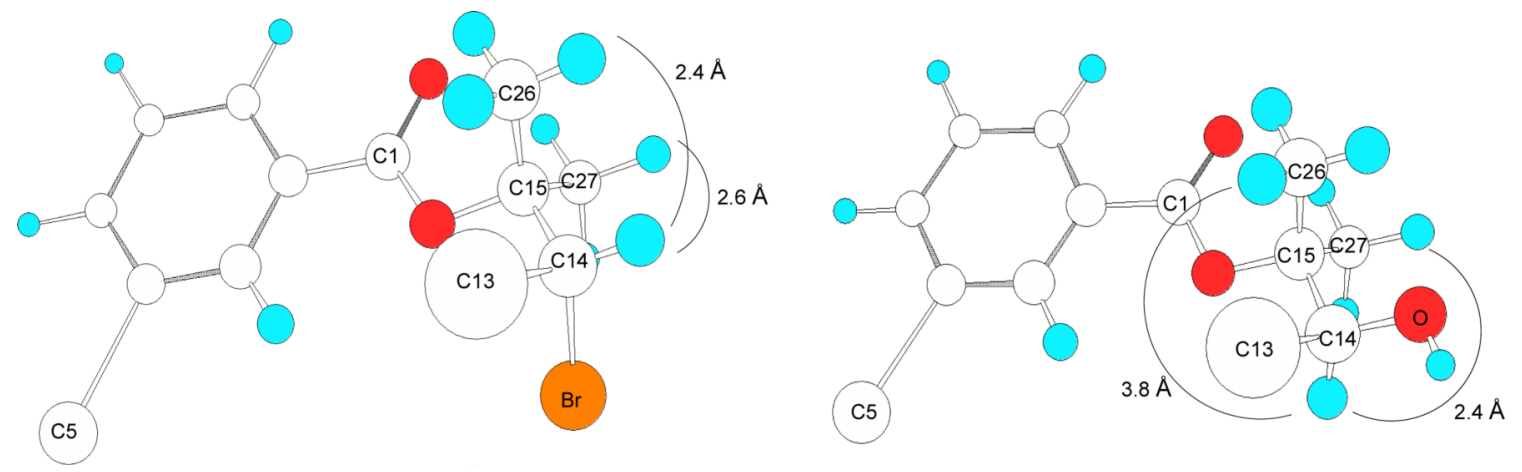

Figure 2.

Partial 3D structures of bromophycolides B (9) and H (6) [left], and bromophycolides G (5) and I (7) [right], predicted from the X-ray crystal structure of 9 (ref. 2). 


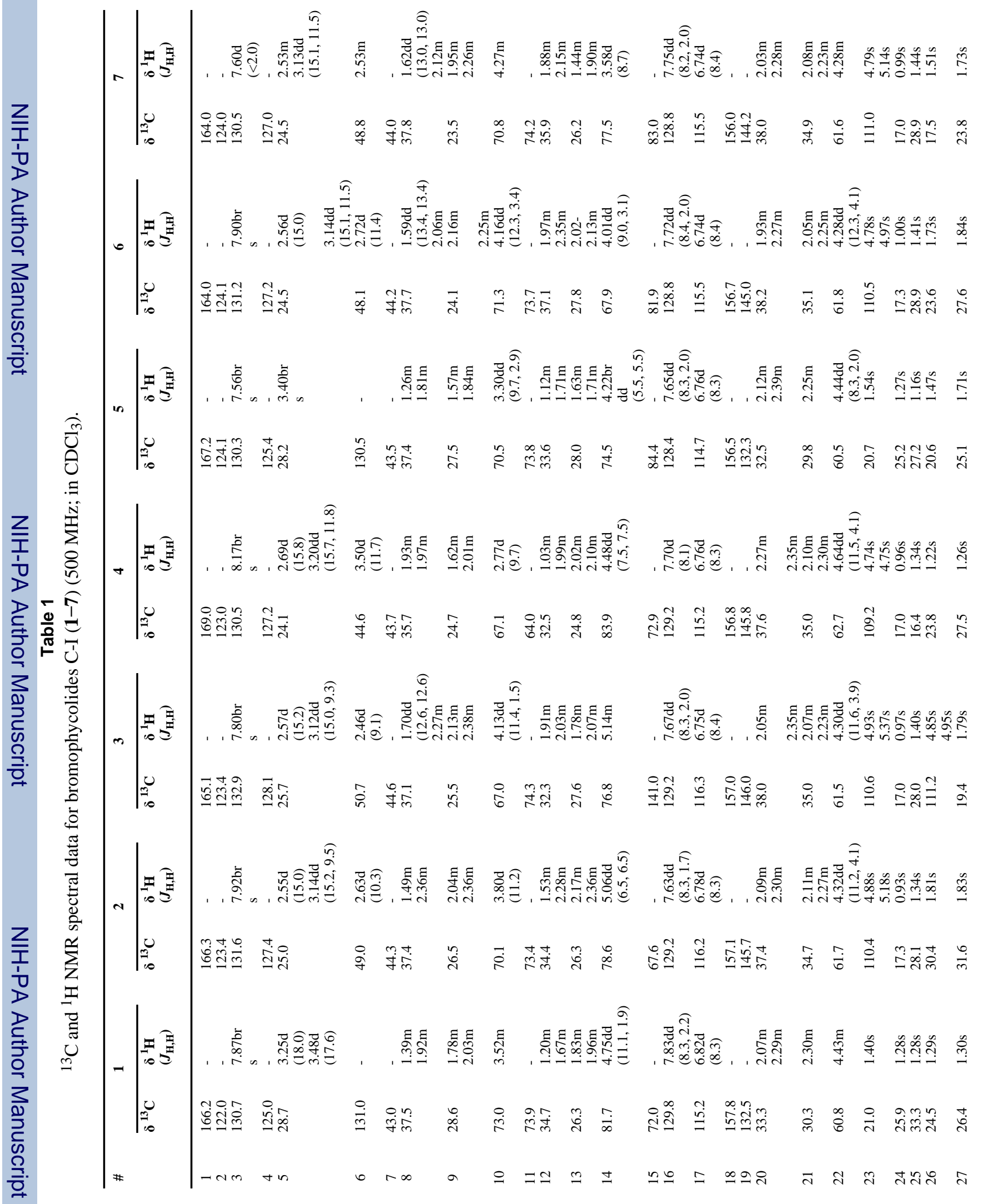




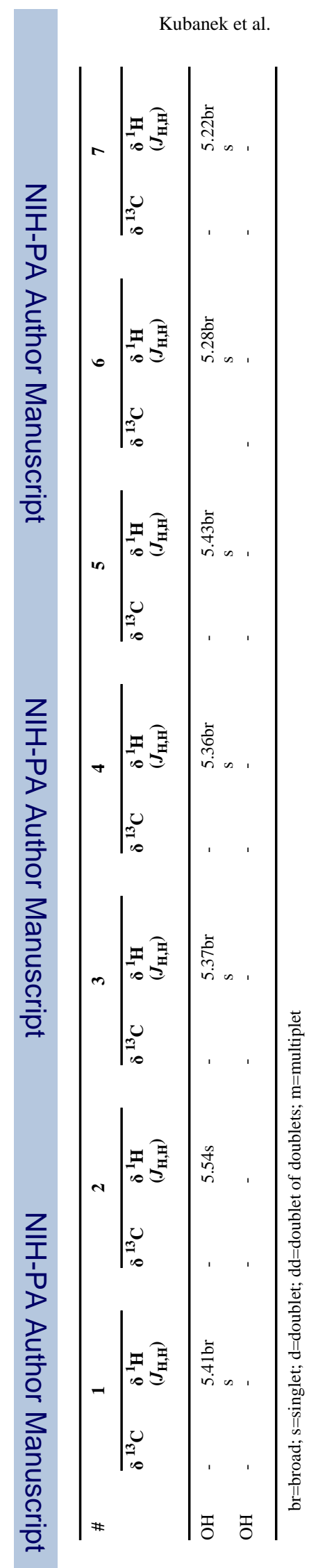

Page 12

J Nat Prod. Author manuscript; available in PMC 2008 September 3. 
Table 2

Pharmacological activities of bromophycolides C-I (1-7).

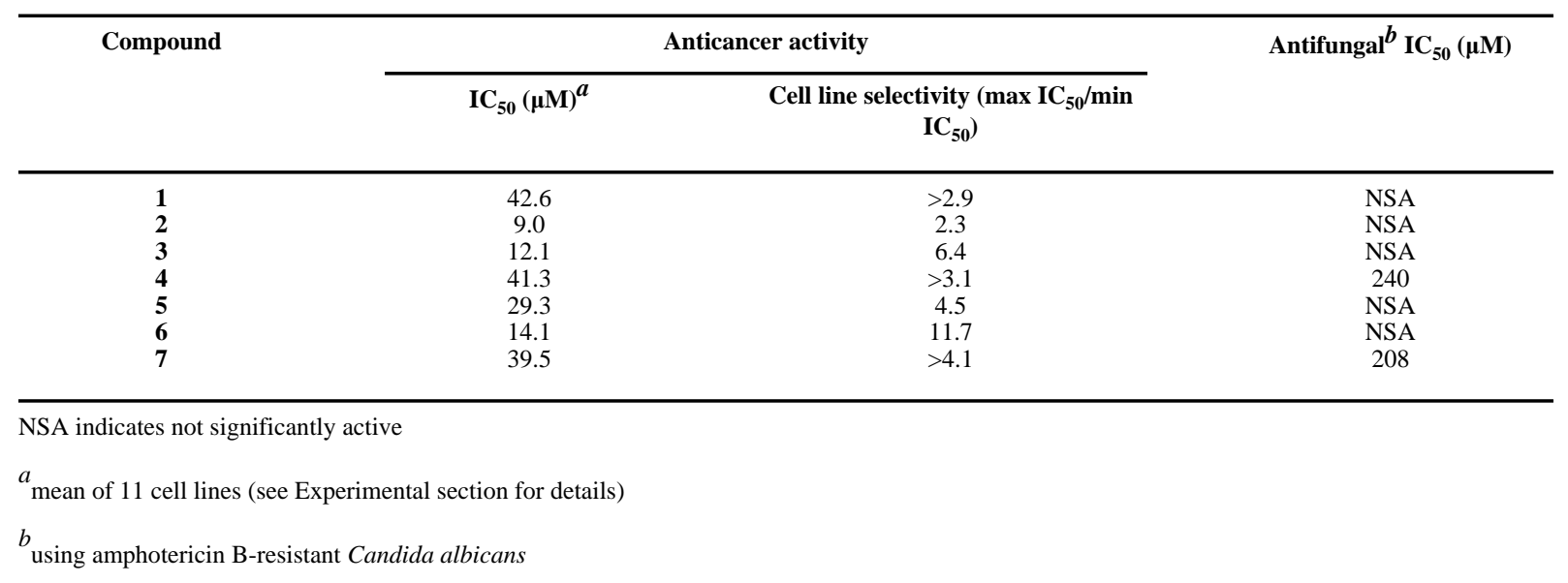

